\title{
Characterization of the plastic behaviour of AA6016-T4 aluminium alloy
}

\author{
Liana Părăianu ${ }^{1, a}$, Dorel Banabic ${ }^{1, b}$ \\ ${ }^{1}$ CERTETA Research Centre, Technical University of Cluj-Napoca, Memorandumului 28, 400114 \\ Cluj-Napoca, Romania \\ aparaianu@tcm.utcluj.ro (corresponding author) \\ bbanabic@tcm.utcluj.ro
}

\begin{abstract}
Keywords: Mechanical characteristics; Aluminium alloy; Yield surface; Plane strain.
\end{abstract}
\begin{abstract}
The current trend in the automotive industry consists in decreasing the weight of the car body to reduce the fuel consumption and the air pollution. This can be done by using low-density materials such as the aluminium alloys having good formability. A frequently used aluminium alloy in the manufacturing of the car body components is AA6016-T4. The paper presents a full mechanical characterization of this material with $1 \mathrm{~mm}$ thickness. The investigation starts by performing tensile tests on specimens cut at $0^{\circ}, 45^{\circ}$ and $90^{\circ}$ from the rolling direction. For each direction, the yield stress and the anisotropy coefficients are determined. The mechanical parameters of the Hollomon hardening law are determined using the experimental data obtained on samples cut along the rolling direction. Besides the uniaxial parameters, the equibiaxial yield stress and the equibiaxial coefficient of anisotropy are determined by performing bulge tests and compression tests, respectively. The yield surface is characterized in the first quadrant not only by the uniaxial and equibiaxial yield stresses but also by the yield stresses associated to the plane strain status. An experimental strategy for determining the plane strain parameters based on bulge tests is described in the paper. The characterization of the AA6016-T4 aluminium alloy ends with the determination of the forming limit diagram. The tests used for determining the limit strains are the punch stretching and hydraulic bulging.
\end{abstract}

\section{Introduction}

The reports issued by the European automotive industry show that the average mass of the European vehicles has dramatically increased. As a consequence, the fuel consumption and the air pollution have also increased. The current legislation together with the requirements coming from the clients, enforce car manufacturers to add parts to the safety system, extra comfort, etc. This phenomenon is known as the "weight spiral" [1]. A strategy to reduce the mass of the car body consists in using low-density materials with good formability. Aluminium alloys are the ideal lightweight materials that can be used for this purpose [2]. At the same time, the economical environment enforces the automotive industry to reduce the time for part design in order to increase the efficiency and also to prevent the material waste. The use of the Finite Element (FE) simulation is a well known strategy that can be used to reduce the time consumption and the cost of the product development, as well as to optimize the technical solutions.

The numerical simulation of a sheet metal forming process demands mathematical constitutive laws describing the anisotropic behaviour of the material. To capture with enough accuracy the plastic deformation, complex formulations of material models have been developed and implemented in finite element programmes. Their identification procedures require mechanical parameters determined from various experimental tests.

The latest yield criteria [3] implemented in the finite element programmes necessitates in the identification procedure a large number of the mechanical parameters. Sometimes the required mechanical parameters are not available. In order to avoid as much as is possible this situation, some yield criterion can be used with less mechanical parameters. In [4] authors studied the influence of the mechanical parameters on the accuracy of the sheet metal forming simulation based on such a flexible yield criterion. 
The forming limit curve (FLC) is an efficient tool used as a limitation criterion of the strain predicted by the FE simulation. This is the final item used in order to establish the formability of the sheet material. Different theoretical models [3] have been used to calculate the limit strains, some of the approaches are implemented in the finite element programmes. The mechanical parameters of the sheet metals have a strong influence on the FLC. A study regarding to this issue is presented in [5].

In this paper, a characterization at the macro scale of the AA6016-T4 aluminium alloy is presented. According to [6], this material is often used for manufacturing the outer panels of the car body, while for the inner panels AA5182-0 aluminium alloy is used. A study regarding to anizotropy and formability of this material is presented in [7]. The investigation starts by performing tensile tests in order to determine the uniaxial parameters and the coefficients of Hollomon's hardening law. The uniaxial parameters are the yield stresses and coefficients of plastic anisotropy determined on samples cut at $0^{\circ}, 45^{\circ}$ and $90^{\circ}$ from the rolling direction. In the equibiaxial region, the material is characterized by the corresponding yield stress and anisotropy coefficient. Two major yield stresses in plane strain tension at $0^{\circ}$ and $90^{\circ}$ from rolling direction are also determined by means of a bulge test. Finally, the forming limit curve of the AA6016-T4 sheet metal is determined.

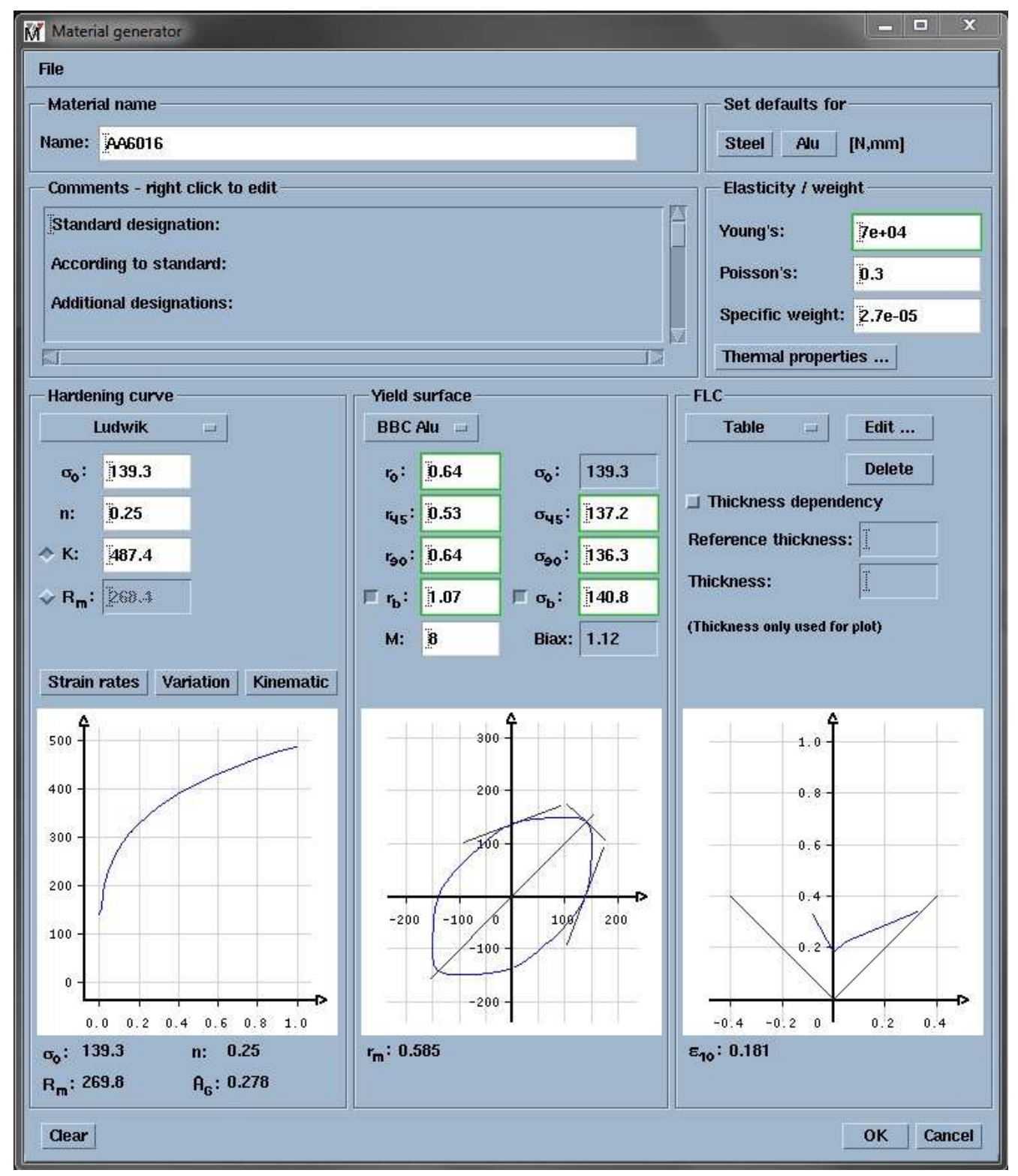

Fig. 1. Material generator window from AUTOFORM [8] 
Fig.1 shows the material generator graphical user interface (GUI) provided by AUTOFORM [8]. One may notice that the GUI allows the user to introduce the experimental data in order to compute the parameters involved in the hardening law, yield criterion and FLC. These model items reflect the anisotropic behaviour and the formability of the material. By having a full characterization of the material, a finite element simulation can be performed.

\section{Determination of the mechanical parameters}

Investigated material. The material used in this study is an AA6016-T4 aluminium alloy with $1 \mathrm{~mm}$ thickness. The chemical composition of the material is presented in Table 1 [EN 573-3:2007]. The alloy belongs to the $6 \mathrm{xxx}$ series and it has been delivered in a T4 status (solution heat treated and naturally aged). The material is a precipitation hardening aluminium alloy, containing magnesium and silicon as its major alloying elements.

Table 1. Chemical composition of the AA6016-T4 aluminium alloy [\%]

\begin{tabular}{|c|c|c|c|c|c|c|c|c|c|c|}
\hline $\mathbf{S i}$ & $\mathbf{F e}$ & $\mathbf{C u}$ & Mn & Mg & $\mathrm{Cr}$ & $\mathbf{Z n}$ & Ti & $\begin{array}{l}\text { Total } \\
\text { percent of } \\
\text { the unlisted } \\
\text { metallic } \\
\text { elements }\end{array}$ & $\begin{array}{l}\text { Individual } \\
\text { percent of } \\
\text { the unlisted } \\
\text { metallic } \\
\text { elements }\end{array}$ & $\begin{array}{l}\text { Aluminium } \\
\text { Min. }\end{array}$ \\
\hline $\begin{array}{l}1.0- \\
1.5\end{array}$ & 0.5 & 0.2 & 0.20 & $\begin{array}{l}0.25- \\
0.6\end{array}$ & 0.10 & 0.20 & 0.15 & $<=0.15$ & $<=0.05$ & Remainder \\
\hline
\end{tabular}

Uniaxial mechanical parameters. In order to determine the uniaxial mechanical parameters, tensile tests have been performed on specimens cut at $0^{\circ}, 45^{\circ}$ and $90^{\circ}$ from the rolling direction. The experiments provided the values of the following mechanical parameters: yield stresses $\left(\mathrm{Y}_{0}, \mathrm{Y}_{45}\right.$ and $\left.\mathrm{Y}_{90}\right)$ and anisotropy coefficients $\left(\mathrm{r}_{0}, \mathrm{r}_{45}\right.$ and $\left.\mathrm{r}_{90}\right)$. The hardening has been described by the Hollomon's power law. The mechanical parameters of the hardening law result from a tensile test performed on samples cut along the rolling direction.

The Hollomon hardening law has the following mathematical formulation:

$$
\mathrm{Y}_{0}=\mathrm{K} \varepsilon^{\mathrm{n}} \text {. }
$$

where $\mathrm{K}$ and $\mathrm{n}$ are the mechanical parameters determined by fitting the results of tensile tests.

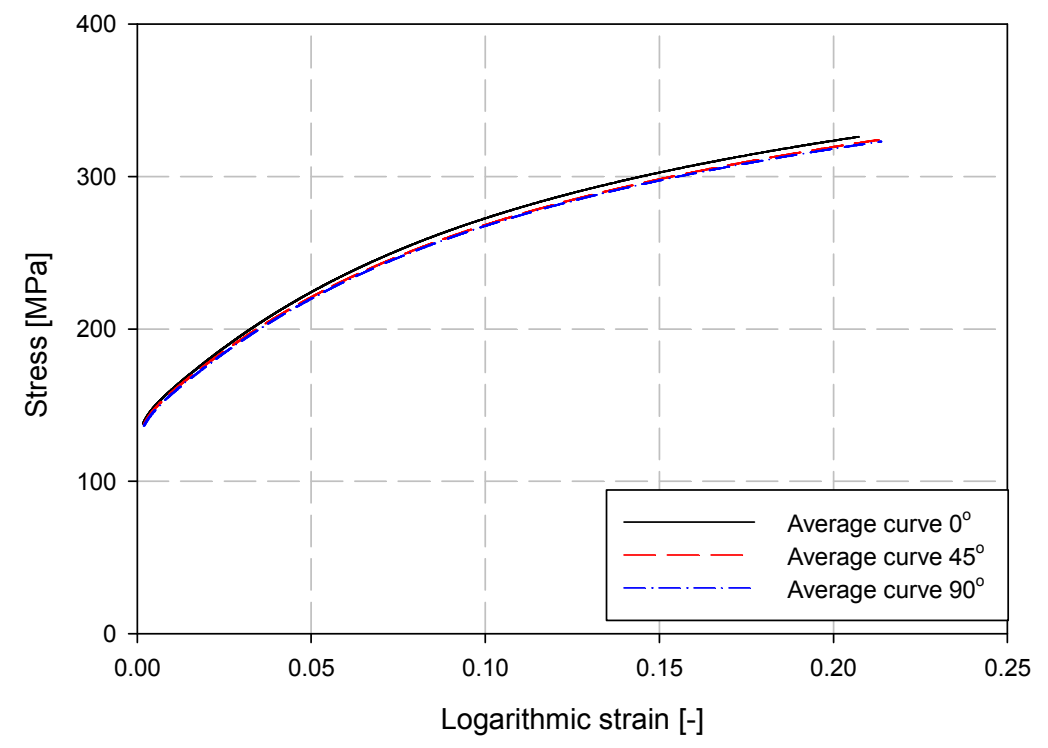

Fig. 2. Averaged stress-strain curves determined from tensile tests 
The experiments have been carried out using a Zwick-Roell $150 \mathrm{kN}$ universal tensile testing machine equipped with an extensometer with $20 \mathrm{~mm}$ gauge-length. The experimental data has been processed using testXpert II software.

Tabel 2. Uniaxial mechanical parameters of the AA6016-T4 sheet metal (1 mm thickness)

\begin{tabular}{cccccc}
\hline Angle & $\mathbf{r}[-]$ & $\mathbf{Y}_{\boldsymbol{\theta}}[\mathbf{M P a}]$ & $\mathbf{U T S}_{\boldsymbol{\theta}}[\mathbf{M P a}]$ & $\mathbf{n}[-]$ & $\mathbf{K}[\mathbf{M P a}]$ \\
\hline $\mathbf{0}^{\mathbf{0}}$ & 0.64 & 139.26 & 264.26 & 0.25 & 487.44 \\
$\mathbf{4 5}^{\mathbf{0}}$ & 0.53 & 137.23 & 261.22 & 0.26 & 483.96 \\
$\mathbf{9 0}^{\mathbf{0}}$ & 0.64 & 136.30 & 260.10 & 0.25 & 481.57 \\
\hline
\end{tabular}

For each direction mentioned above, five tensile tests have been performed. Fig. 1 shows the averaged stress-strain curves resulted from the experiments. In Table 2, the mean values of the following uniaxial mechanical parameters have been listed: yield stresses, anisotropy coefficients, tensile strengths (UTS), coefficients of Hollomon's hardening law. The strain rate used in the tensile tests has been set to $10^{-3} \mathrm{~s}^{-1}$.

Biaxial mechanical parameters. In order to describe the equibiaxial region, two mechanical parameters have been experimentally determined: equibiaxial yield stress and equibiaxial coefficient of anisotropy. The equibiaxial yield stress resulted from a bulge test. Fig. 3 shows the mechanical configuration of the hydraulic bulging device [9].

The notations used in the sketch have the following significance:

q - blank holding force;

$\mathrm{p}$ - current level of the pressure during the bulging process;

$\mathrm{s}$ - current thickness of the deformed specimen in the polar region;

$\rho-$ current bulge radius.

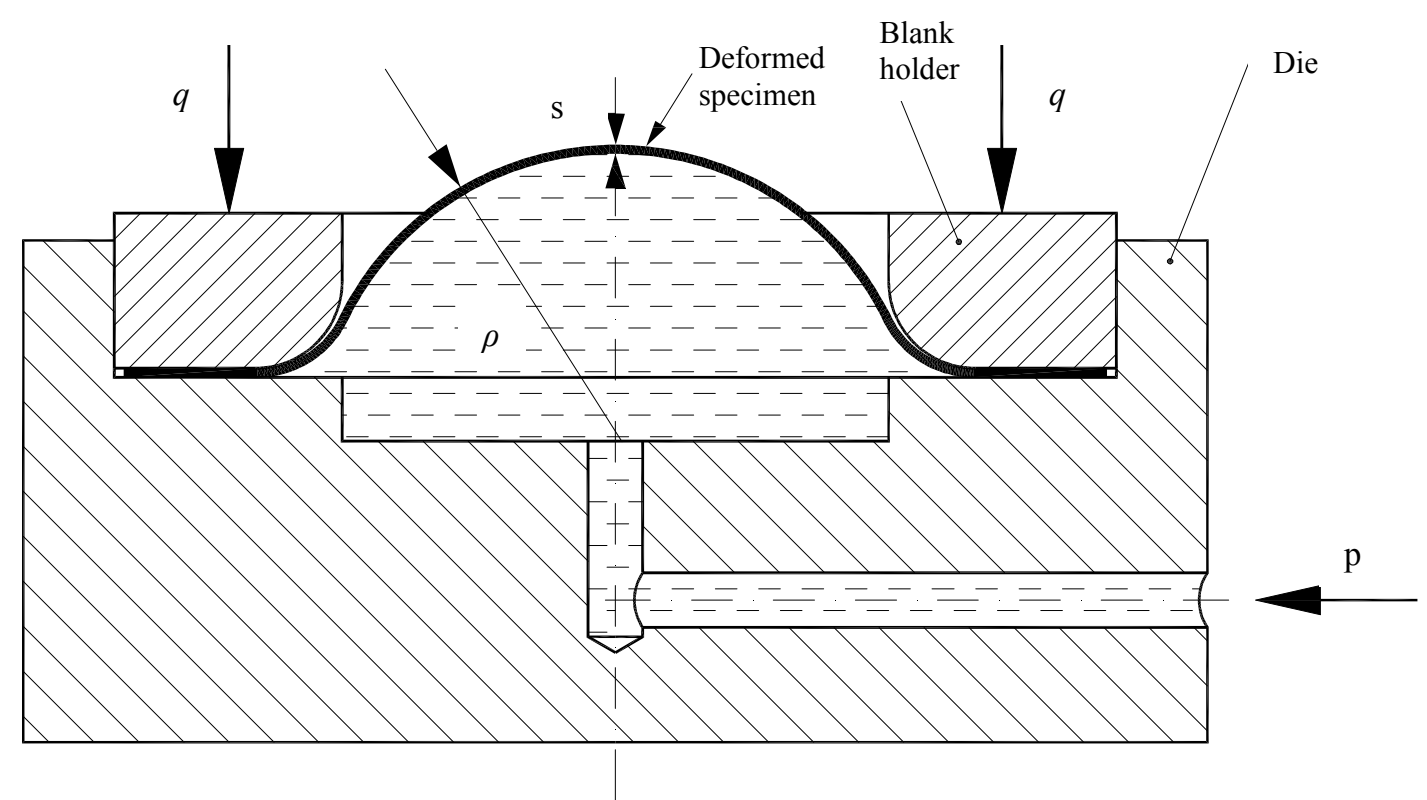

Fig. 3. Principle of the hydraulic bulge test

Fig. 4 shows the experimental equipment used to perform the bulge tests and to process the experimental data sets. The specimen bulging is the result of the pressure applied on its lower face. The evolution of the pressure is controlled by the ERICHSEN device. The polar strain field and the bulge radius are obtained and processed by the ARAMIS 3D measurement system.

One assumes that during the bulge test, the sheet metal behaves as a membrane under plane-stress conditions. Thereby, the Laplace equation can be applied in order to determine the stress level in the polar region: 


$$
\frac{\sigma_{1}}{\rho_{\mathrm{RD}}}+\frac{\sigma_{2}}{\rho_{\mathrm{TD}}}=\frac{\mathrm{p}}{\mathrm{s}}
$$

where $\sigma_{1}$ and $\sigma_{2}$ represents the principal stresses, $\rho_{\mathrm{RD}}$ and $\rho_{\mathrm{TD}}$ are the bulge radii along RD and $\mathrm{TD}$, respectively. In the equibiaxial case, the principal stresses and the corresponding radii are almost equal, i.e. $\sigma_{1} \cong \sigma_{2}=\sigma_{\mathrm{b}}$ and $\rho_{\mathrm{RD}} \cong \rho_{\mathrm{TD}}=\rho$. The common value of the principal stresses $\left(\sigma_{\mathrm{b}}\right)$ is the so-called equibiaxial yield stress. This quantity can be evaluated with the following formula:

$$
\sigma_{\mathrm{b}}=\frac{\mathrm{p} \rho}{2 \mathrm{~s}} \text {. }
$$

The current thickness $\mathrm{s}$ is computed according to the material volume conservation and assuming the equality of the principal strains. In order to calculate the equibiaxial yield stress an energetic method has been used. The method consists in equating the plastic work dissipated in equibiaxial and uniaxial traction regimes. The method is detailed in [10]. By following that procedure, the value of equibiaxial yield stress has been established at $140.76 \mathrm{MPa}$.

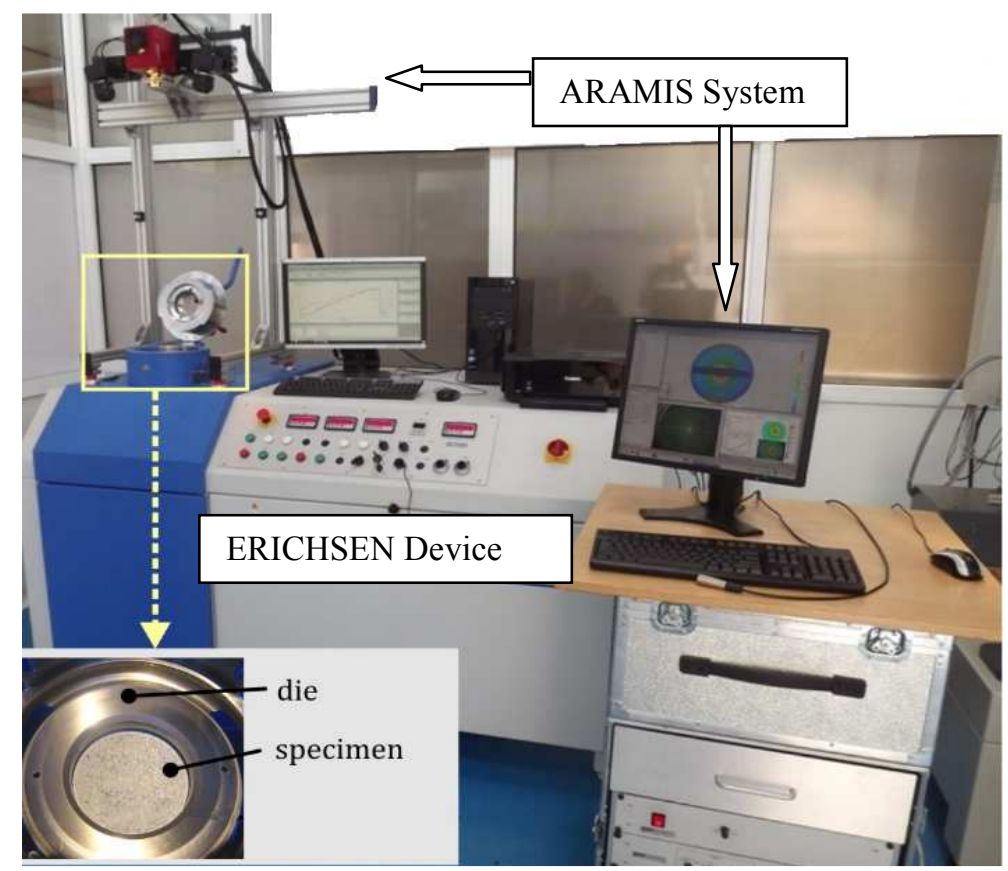

Fig. 4. Experimental stand consisting in the ERICHSEN bulge test device and the ARAMIS 3D optical system

For determining the equibiaxial anisotropic coefficient [11], $10 \mathrm{~mm}$ disc plate has been subjected to thickness compression tests. The friction effects have been reduced by using Teflon foils with 0.15 $\mathrm{mm}$ thickness. The equibiaxial anisotropic coefficient has been computed by using the following formula:

$$
\mathrm{r}_{\mathrm{b}}=\frac{\mathrm{d} \varepsilon_{\mathrm{TD}}}{\mathrm{d} \varepsilon_{\mathrm{RD}}} .
$$

where

$$
\mathrm{d} \varepsilon=\ln \frac{\mathrm{D}_{\mathrm{f}}}{\mathrm{D}_{\mathrm{i}}}
$$

where $D_{f}$ and $D_{i}$ is the final and initial diameter of the specimen.

The value of the equibiaxial anisotropic coefficient has been established at 1.069. 


\section{Determination of the yield surface}

An accurate description of the mechanical behaviour of a material consists in the experimental determination of the yield surface. The unaixial and equibiaxial tests provided four yield stresses. Those are the yield stresses determined on samples cut at $0^{\circ}, 45^{\circ}$ and $90^{\circ}$ from the rolling direction as well as equibiaxial yield stress. In the following, an experimental strategy to determine the major stresses in the plane strain condition to $0^{\circ}$ and $90^{\circ}$ will be presented.

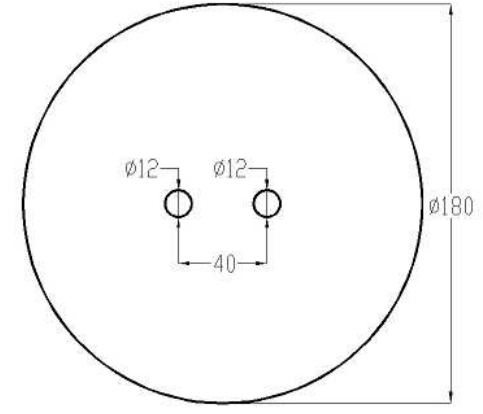

Fig. 5. Geometry of test specimen (measures in $[\mathrm{mm}]$ )

The plane strain status is very difficult to obtain in laboratory tests due to the fact that a zero extension-compression should achieved along a certain direction. The classical experimental method used to obtain the plane strain yield stress is the tensile test performed on the wide samples [11]. The new test proposed to attain the plane-strain is based on the principle of the bulge process. The geometry of the specimen is shown in Fig. 5. The specimen is placed on the top surface of a carrier blank cut from the same material (see Fig. 3). Under the action of the oil pressure, both the specimen and the carrier deform in the same time.

Fig. 6 shows the major strain and the thickness reduction in the central region of the specimen, i.e. between the circular holes. In that particular region, the plane strain condition has been observed.

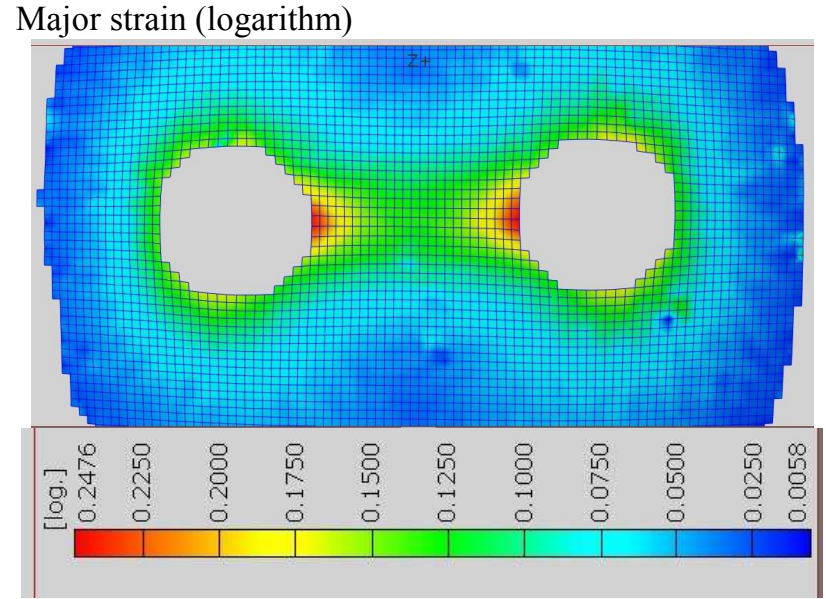

a)

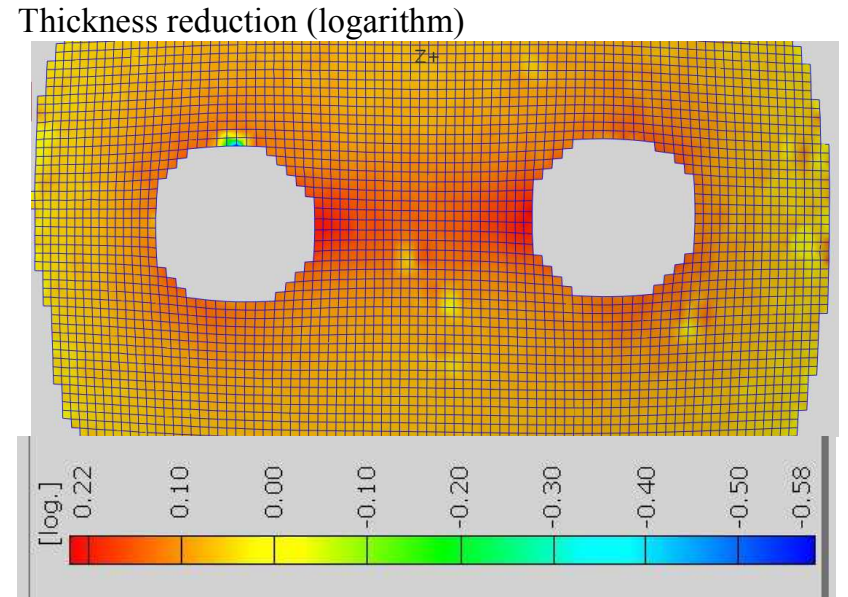

b)

Fig. 6. Major strain field a) and thickness reduction b) on the specimen obtained at the same stage

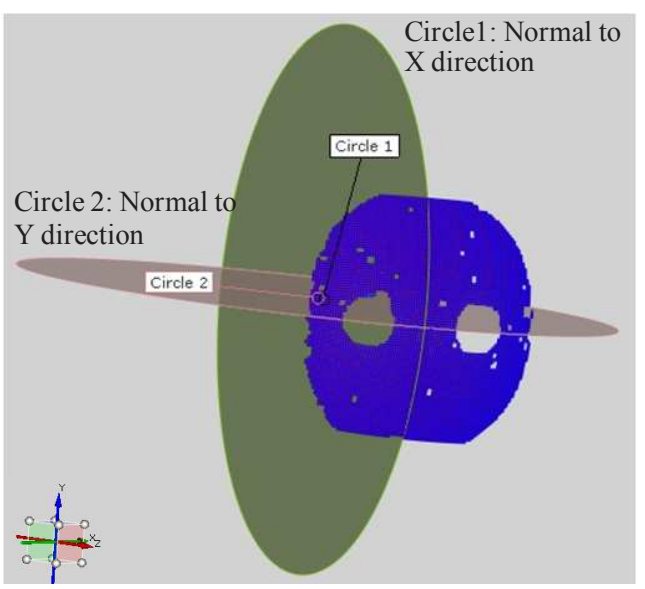

Fig. 7. Determination of the radii along RD and DT using the ARAMIS
Fig. 7 shows the determination of the radii along RD and DT using the ARAMIS Software. The software allows the user to select the area used for calculating the best circular approximation. The radii automatically determined during the bulge process have been used in Eq. (2). Based on those calculations and using a yield criterion major stresses in the plane strain condition to $0^{\circ}$ and $90^{\circ}$ have been computed. If the BBC2005 [13] yield criterion, as implemented in the AUTOFORM finite element programme, is been adopted, the values of the major stresses have been established at 146.051 MPa and 143.976 MPa respectively. 


\section{Determination of the forming limit curve}

The FLC is a curve relating pairs of principal limit strains, which can be obtained at the surface of the sheet metal during a forming process prior to the occurrence of some defects (necking, fracture, etc.). The experimental determination of FLC followed the instructions of the international standard ISO 12004-2 [14]. The geometry of the specimens is presented in figure 8. By varying the width of the specimen, different strain states can be achieved. The correspondence between the geometry of the specimens and the regions of the forming limit diagram is clearly defined in figure 8 . The specimens are subjected to a punch stretching. In order to reduce the friction between the specimen and the rigid punch, Teflon foils have been used. Even so, there is not possible to reach the equibiaxial limit strains $\left(\varepsilon_{1}=\varepsilon_{2}\right)$. In that case, hydraulic bulging is the simplest procedure that can be used to obtain such a state.
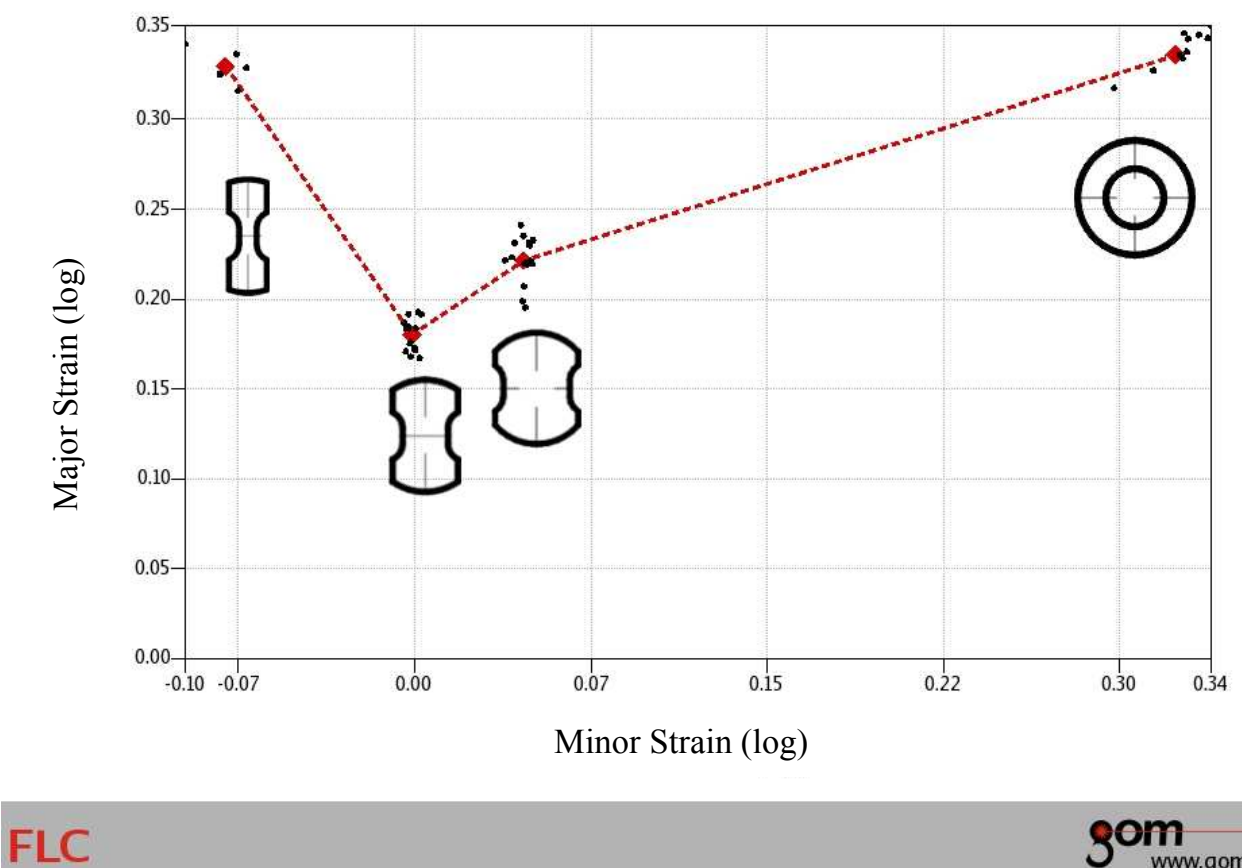

gom

Fig. 8 Correspondence between the geometry of the specimens and the regions of the forming limit diagram

The strain distribution on the surface of specimens has been measured with an ARAMIS 3D optical system (see Fig. 4). The measurements have been performed using a "position-dependent" method. The limit strain has been determined according to Bragard's method. In the top of the figure 8, the forming limit curve determined for AA6016-T4 aluminium alloy has been plotted.

\section{Conclusions}

In this paper, a characterization of the plastic behaviour of the AA6016-T4 aluminium alloy with 1 $\mathrm{mm}$ thickness has been presented. The values of the uniaxial and equibiaxial mechanical parameters have been experimentally determined. An accurate determination of the yield surface has been accomplished by supplementing the input data with the yield stresses associated to the plane strain conditions along the rolling and transverse directions, respectively. The plane strain characteristics have been determined using a new experimental methodology based on the principle of the bulge test. The methodology consists in the controlled deformation of a pierced specimen clamped against a carrier blank. The minor yield stresses in plane strain conditions have been evaluated using the BBC 2005 yield criterion. The proposed methodology provides very good results. The mechanical characterization of the material ends with the determination of the forming limit curve. 
ACKNOWLEDGMENT: The research performed by the first author has been supported from a scholarship provided by the project "Development and support of multidisciplinary postdoctoral programmes in major technical areas of national strategy of Research - Development - Innovation" 4D-POSTDOC, contract no. POSDRU/89/1.5/S/52603, project co-funded by the European Social Fund through Sectorial Operational Programme Human Resources Development 2007-2013, as well as from the logistic funding provided by CNCS in the frame of the Project PCCE 100/2010.

\section{References}

[1] Information on http://www.alueurope.eu

[2] J. Hirsch, Aluminium in innovative light-weight car design, SLC Conference "Latest Developments for Lightweight Vehicle Structures", Wolfsburg, Germany, (2009).

[3] D. Banabic, Sheet Metal Forming Processes. Constitutive modelling and numerical simulation, Springer, Heidelberg, Berlin, (2010).

[4] D. Banabic, M. Sester, Influence of material models on the accuracy of the sheet forming simulation, Materials and Manufacturing Processes, 27(2012) 304-308.

[5] L. Părăianu, S. Comşa, I. Bichiş, D. Banabic, Influence of the Mechanical Parameters on the Forming Limit Curve, Steel Research International (2011) 744-749.

[6] J. Hirsch, Virtual Fabrication of Aluminium Products-Microstructural Modelling in Industrial Aluminium Fabrication Processes, Wiley-VCH Verlag GmbH\&Co., Weinheim, 2006.

[7] D. Banabic, Anisotropy and formability of AA5182-0 aluminium alloy sheets, Annales of CIRP 53 (2004) 219-222.

[8] Information on http://www.autoform.com

[9] S. Comsa, G. Cosovici, P. Jurco, L. Paraianu, D. Banabic, Simulation of the hydroforming process using a new orthotropic yield criterion, Journal of Materials Processing Technology, $157-158$ (2004) 67-74.

[10] D.J. Lege, F. Barlat, J.C. Brem, Characterization and modeling of the mechanical behavior and formability of a 2008-T4 sheet sample, International Journal of Mechanical Sciences, 31 (1989) 549-563.

[11] F. Barlat, J.C. Brem, J.W. Yoon, K. Chung, R.E. Dick, S.-H. Choi, F. Pourboghrat, E. Chu, D.J. Lege, Plane stress yield function for aluminium alloy sheets. Part 1. Theory, International Journal of Plasticity, 19 (2003), 1297-1319.

[12] D. Banabic, H. Aretz, D.S. Comşa, L. Părăianu, An improved analytical description of orthotropy in metallic sheets, International Journal of Plasticity 21 (2005) 493-512.

[13] D. Banabic et al., Influence of constitutive equations on the accuracy of prediction in sheet metal forming simulation, Numisheet 2008, September 1-5, - Interlaken, Switzerland, (2008) $37-42$.

[14] ISO 12004-2/2008 - Metallic materials — Sheet and strip — Determination of forming-limit curves - Part 2: Determination of forming-limit curves in the laboratory. 